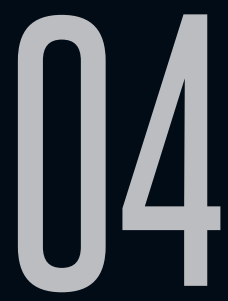

\title{
A FICÇÃO CIENTÍFICA DE RACHEL DE QUEIROZ
}

Ramiro Giroldo (UFMS/CNPq-FUNDECT)

Recebido em 27 fev 2016. Ramiro Giroldo - Professor Adjunto A do Curso de Aprovado em 01 abr 2016. Letras da Universidade Federal de Mato Grosso do Sul; Mestre em Estudos de Linguagens pelo Programa de Pós-Graduação Mestrado em Estudos de Linguagens da Universidade Federal de Mato Grosso do Sul; Doutor em Letras pela Faculdade de Filosofia, Letras e Ciências Humanas da Universidade de São Paulo; Pesquisador DCR nível C com financiamento CNPq/FUNDECT; Integrante do Núcleo de Estudos Historiográficos de Mato Grosso do Sul (NEHMS); Autor do livro Ditadura do Prazer: sobre ficção científica e utopia (Ed. UFMS, 2013). Contato: r_giroldo@yahoo. com.br; ramiro.giroldo@ufms.br

Resumo: O artigo trata do único texto de ficção científica de Rachel de Queiroz, o conto "MaHôre", por meio da discussão de duas apropriações complementares: a apropriação por parte de Queiroz de procedimentos da ficção científica e a que o protagonista do conto efetua de uma cultura hegemônica. Assim, é traçado um questionamento acerca da constituição de nosso cânone literário, bem como da maneira com que tem sido tradicionalmente avaliada a relação entre a produção literária brasileira e a estrangeira. O artigo também trata do caráter atípico do conto "Ma-Hôre" em relação ao restante da produção literária de Rachel de Queiroz. Na abordagem das questões relativas à constituição 
de cânone literário brasileiro, é levada em conta a noção de "sistema literário" apresentada por Antonio Candido, bem como o caráter nacionalista da produção literária nacional. $\mathrm{O}$ artigo se ampara na conceituação da ficção científica como gênero literário proposta por Darko Suvin, e também em considerações críticas de Mary Elizabeth Ginway sobre o conto "Ma-Hôre". Palavras-chave: Rachel de Queiroz; Ficção científica; Cânone literário brasileiro; Apropriação.

Abstract: The paper discusses the only science fiction work written by Rachel de Queiroz, the shortstory "Ma-Hôre". It discusses two complementary appropriations: the one promoted by Queiroz of the procedures of the science fiction and the one promoted by the short-story protagonist of a hegemonic culture. Thus, it is traced a questioning of our literary canon and of the relationship between the Brazilian literary production and the foreign literary production as it has been traditionally evaluated. The article deals with the atypical characteristics of the short-story "Ma-Hôre" in relation to the regionalist body of work of Rachel de Queiroz. In the approach of the constitution of the Brazilian literary canon, it is taken into account the notion of "literary system" by Antonio Candido, as well as the nationalist characteristics of the national literary production. The article uses the notion of science fiction as a literary genre proposed by Darko Suvin and discusses Mary Elizabeth Ginway's reading of the short-story "Ma-Hôre".

Keywords: Rachel de Queiroz; Science fiction; Brazilian literary canon; Appropriation.

O conto "Ma-Hôre", de Rachel de Queiroz, foi apresentado ao editor Gumercindo Rocha Dórea em resposta a um convite para colaboração na antologia de contos de ficção científica Histórias 
do acontecerá - título este, aliás, sugerido pela própria autora ${ }^{1}$. À frente da editora que carregava suas iniciais, a Edições GRD, Dórea fomentou, no decorrer da década de 1960, a produção nacional de textos de ficção científica. Uma de suas estratégias de popularização e difusão do gênero no Brasil era justamente convidar autores consagrados, aparentemente estranhos à ficção científica, para as antologias por ele organizadas: sua casa editorial também publicou, por exemplo, obras de autores como Dinah Silveira de Queirós, Antonio Olinto, Clóvis Garcia e Ruy Jungmann.

Em 2011, "Ma-Hôre" foi republicado na antologia Páginas do futuro: contos brasileiros de ficção científica, organizada por Braulio Tavares. A republicação não inclui modificações no conto, apenas a revisão segundo o Novo Acordo Ortográfico da Língua Portuguesa. Essa é a edição usada para a escrita do presente texto.

Abordar a produção de ficção científica de autores anexados ao cânone literário brasileiro, caracterizado por um conjunto de obras estranhas ao gênero, equivale a demarcar a presença de manifestações literárias paralelas às oficialmente instituídas. Adota-se, assim, uma postura avessa à homogeneização de autores e períodos promovida pela historiografia literária tradicional em seu esforço de ignorar a heterogeneidade e o entrelugar que são, na verdade, próprios da literatura e das manifestações culturais em geral.

Antonio Candido, em sua obra Formação da literatura brasileira: momentos decisivos, elabora em pormenores a noção de "sistema

1 Nas palavras de Braulio Tavares, que reeditou o conto em 2011: “O conto 'Ma-Hôre' surgiu de um convite feito por Gumercindo Rocha Dórea para participar de uma antologia de contos de ficção científica. Rachel enviou uma história chamada 'História do acontecerá', e o editor gostou tanto que pediu o título emprestado para a própria antologia, uma das obras marcantes da Primeira Onda da FC brasileira nos anos 1960" (TAVARES, 2011, p.20). 
literário", segundo a qual a literatura apenas se constitui enquanto tal quando se integra a um esquema que inclui meios de divulgação, público e, por fim, novos escritores que constroem suas obras em diálogo com as precedentes - quando tais condições não se estabelecem, há apenas "manifestações literárias". A periodização literária é, em decorrência, pautada pelas obras que alcançam repercussão sócio-cultural e a posterior acolhida pela tradição - em suma, as obras que integram um sistema. Em Iniciação à literatura brasileira, Candido formula didaticamente o ponto:

Entendo aqui por sistema a articulação dos elementos que constituem a atividade literária regular: autores formando um conjunto virtual, e veículos que permitem o seu relacionamento, definindo uma 'vida literária': públicos, restritos ou amplos, capazes de ler ou ouvir as obras, permitindo com isso que elas circulem e atuem; tradição, que é o reconhecimento de obras e autores precedentes, funcionando como exemplo ou justificativa daquilo que se quer fazer, mesmo que seja para rejeitar (1999, p.14-15).

Candido chama nossa literatura de "empenhada" em se constituir como autoafirmação brasileira, o que se deve à tentativa de criar uma literatura (e um país) independente das amarras metropolitanas. Valorizou-se o uso de temas e imagens relacionados ao Brasil, e os textos a adotá-los foram mais prontamente integrados ao sistema - e ao cânone.

Anteriormente à formalização do conceito de sistema literário promovida por Candido, os critérios valorativos pareciam regular aprioristicamente a delimitação dos períodos da historiografia literária. Critérios pautados pela presença ou não de feições 
características do Brasil, na valoração de obras que desde a superfície textual corroborassem com o projeto de cunhar uma feição tipicamente nacional. É nesses termos que Afrânio Coutinho, em Conceito de literatura brasileira, coloca o ponto:

De Wolf a Sílvio Romero, e de José Veríssimo a Ronald de Carvalho, o problema da periodização vincula-se ao conteúdo nacional da literatura, e a história literária é a verificação desse crescente sentimento, a princípio mascarado de nativismo, e cada vez tornado mais consciente até abrolhar em verdadeiro sentimento nacional (s.d., p.22).

Por outro lado, a noção de sistema literário, conforme formulada por Antonio Candido, privilegia a observação de condições objetivas de produção e recepção crítica e artística. Evita-se que um critério (o nacionalista) se imponha a priori no momento de delimitar tendências, movimentos e períodos literários. Dessa forma, o conceito permite que a periodização vá algo além da mera busca por conteúdos nacionalistas em cada obra, assim promovendo um olhar mais integrado das dinâmicas de produção, recepção e valoração. Não há, nesse caso, o interesse de abordar a periodização de acordo com critérios valorativos concebidos previamente, mas de observar as trocas entre a produção literária e a sociedade que a lê.

A adoção de tal ponto de vista, contudo, pode ainda envolver o risco de privilegiar as obras que encontraram plenas condições de recepção e subsequente institucionalização, bem como o risco de relegar a segundo plano as obras colocadas à margem do cânone por questões estéticas (por serem atípicas e não se enquadrarem na homogeneizadora periodização literária, por exemplo) ou 
extraliterárias (por exemplo, as obras produzidas por grupos historicamente marginalizados, como mulheres e negros). Ora, um cânone literário também se define pelo que exclui; uma cultura pode ser compreendida também pelo que relega às margens.

Ao invés de desprezar a noção de sistema literário manejada pela crítica canônica, o estudo de manifestações literárias esquecidas à margem do cânone pode compreender a formação dos sistemas como índices de aceitação ou exclusão. No caso do conto aqui em pauta, a tendência naturalista de nosso cânone aponta razões para a institucionalização da produção regionalista de Rachel de Queiroz e para o esquecimento de seu conto de ficção científica. Mary Elizabeth Ginway, em sua obra Ficção científica brasileira: mitos culturais e nacionalidade no país do futuro, investiga o esquecimento a encobrir os textos brasileiros de ficção científica. Para tanto, aborda o estudo Tal Brasil, qual romance? - Uma ideologia estética e sua história: o naturalismo, de Flora Sussekind:

[no estudo, Sussekind] nota a preferência canônica por textos que retratem um senso de identidade literária e nacionalismo, enquanto se marginalizam aqueles que lidam com experimentação literária e Alteridade. Ela demonstra a recorrência do impulso realista/naturalista em romances brasileiros publicados durante os períodos de turbulência sócio-econômica, nas décadas de 1880, 1930 e 1970, defendendo que eles propagavam mitos de identidade (Sussekind, Apud GINWAY, 2005, p.29).

Curiosamente, o conto "Ma-Hôre" apenas na superfície escapa à abordagem das particularidades socioculturais brasileiras. Na história de um alienígena pretensamente subdesenvolvido que se vê às voltas com seres oriundos de uma civilização de avançada 
tecnologia, o conto elabora de forma velada as tensas relações entre o Brasil e os países cultural e economicamente hegemônicos.

Os traços prontamente identificáveis como "brasileiros", tais quais a representação do falar de uma determinada região e a ambientação local, se vêem ausentes. Para ler de que forma "MaHôre" se caracteriza como uma representação de uma condição tipicamente brasileira, há a demanda de ir além da superfície textual.

O estudo do conto é bastante significativo para a discussão de questões relativas à formação de nosso cânone, pois tem o potencial de denunciar a fragilidade de posições que pretendem minimizar as contradições dinâmicas próprias da produção e recepção literárias. Trata-se de um conto não costumeiramente lembrado quando se trata de Rachel de Queiroz, pois a princípio destoa do regionalismo nordestino que a tornou conhecida - e não é de interesse de nossa historiografia literária tradicional conceder atenção ao que não pode ser enquadrado no "sistema". No que concerne à condição feminina de Queiroz, cabe assinalar lateralmente que sua inclusão em nossa tradição literária é exceção em um cânone em sua maioria masculino.

O conto destoa da artificial homogeneização imposta à produção de Queiroz porque joga com os paradigmas da ficção científica, gênero estranho ao nosso cânone e ocasionalmente encarado como estrangeiro em seus procedimentos narrativos. Fornece exemplo de tal percepção o ensaio $A$ ficção do tempo: análise da narrativa de science fiction, de Muniz Sodré, que chega a considerar o gênero um mero sinal da hegemonia imperialista em tempos de capitalismo. A conclusão do autor, contudo, não se ampara no estudo de obras 
específicas, apenas em uma noção generalizante da ficção científica - é, portanto, uma crítica ao gênero quase que declaradamente calcada na ignorância de seus traços distintivos.

Por mais que seja pertinente refutar as proposições de Sodré, seu texto não fornece amparo para o diálogo, sendo construído segundo uma lógica que se quer totalizante. Para refutá-la, seria necessário propor análises alternativas das obras discutidas por Sodré, mas o autor não busca analisar pormenorizadamente obras em seu texto. Nesse ponto, Sodré se isola em sua escolha de buscar amparo em noções totalizantes que não encontram, em nenhum momento, amparo em análises da narrativa de ficção científica - ao contrário do que o subtítulo de seu estudo anuncia.

De forma significativa, o conto aqui em pauta trata da própria adoção de paradigmas estrangeiros na abordagem de especificidades brasileiras. Ou seja, elabora ficcionalmente a tensa relação entre uma região afim aos parâmetros de desenvolvimento hegemônicos e outra à margem deles. A a propriação de instrumentos e práticas advindos do centro se dá no conto em duas instâncias complementares: no enredo e no uso dos próprios procedimentos ficcionais característicos da ficção científica. Cuidemos de ambas as instâncias nos próximos parágrafos.

O título do conto, "Ma-Hôre", é o nome de uma pequena criatura alienígena que observa com curiosidade a chegada em seu planeta de uma espaçonave tecnologicamente avançada. Os nativos do planeta Talôi são pelo narrador chamados de "aborígenes", um indicativo da vida afinada à natureza que levam. Seus avanços técnicos são bastante escassos, e dedicam-se à arte, à subsistência 
e à uma contemplação da natureza essencialmente desinteressada de promover nela modificações. Integram-se ao seu planeta e não tentam moldá-lo aos seus interesses.

De acordo com Ginway, o conto elabora paralelos entre o planeta natal do homúnculo e o Brasil: Talôi é um território anfíbio e a maioria das grandes cidades brasileiras "abraçam a costa" (2005, p.55); as artes e a literatura são nos países latino-americanos, entre eles o Brasil, mais desenvolvidas do que "as áreas da ciência e tecnologia, como um paralelo ao desenvolvimento da cultura Talôi" (2005, p.55).

O homúnculo Ma-Hôre é curioso, mas, como seus pares da raça Zira-Nura, nutre um saudável temor das espaçonaves que passam a visitar seu planeta. A que resolve inspecionar, depois que seus tripulantes descem e se afastam para inspecionar o planeta, é a terceira a pousar em Talôi. Nada até a espaçonave, aproxima-se, verifica se não há nenhuma proteção elétrica a servir de escudo e, temeroso, sobe pela escotilha:

Era tentação demais; Ma-Hôre não resistiu, ergueu mais o corpo na crista de uma mareta, escalou o que pra ele era o alto muro da escotilha e, num salto rápido, já estava no interior da nave desconhecida, a água a lhe escorrer do cabelo metálico pelo corpo liso.

Tudo lá dentro era feito na escala dos gigantes; a cabine parecia imensa aos olhos do pequeno humanoide. (...) De repente sentiu que parara o ruído dos instrumentos a operar no casco externo e escutou o trovejo das vozes dos gigantes que se aproximava. Tomado de pânico, o homúnculo ia fugir para a água, quando viu surgir na boca da escotilha uma das cabeças avermelhadas, logo seguida das 
outras três. Era tarde. Correu a se esconder sob um dos assentos; tremia de medo; que Ihe fariam os astronautas gigantes se $o$ apanhassem espionando a sua nave? (QUEIROZ, 2011, p.21-22).

A diferença de escala entre os dois povos, os nativos e os exploradores estrangeiros, é posta em relevo em diversos momentos do trecho acima. Ma-Hôre escala o "alto muro" que para ele é a escotilha, a cabine parece imensa aos seus olhos, enfim, tudo na espaçonave é feito para se adequar às necessidades de uma raça de gigantes. Há uma marcada inferiorização do homúnculo dada pelos traços aparentes, superficiais, notáveis já à primeira vista. A simplicidade dele e da vida a que seus semelhantes aborígenes está habituada é posta em contraponto com a magnitude física e técnica dos exploradores.

O homúnculo permanece escondido e acaba sendo afetado pela atmosfera da espaçonave. Algo no ar aclimatado pelos exploradores afeta-Ihe os sentidos, em uma descrição que remete à euforia provocada pelo excesso de oxigênio. A princípio, sente-se tonto, mas logo é tomado por

(...) uma irresistível vontade de rir, uma alegria irresponsável. Perdeu o medo dos gigantes, pôs-se a cantar; e afinal, roubado de todo controle, saiu do esconderijo, a agitar os braços, dança que lembrava a dos pequenos diabos verdes que atormentam os Zira-Nura nas horas do furacão.

O ruído insólito despertou os astronautas do seu torpor de fadiga. Cuidaram primeiro que era o altofalante, como alguma transmissão extemporânea. Mas deram com os olhos no pequeno humanoide, a dançar e a rir, sacudindo a juba negra (QUEIROZ, 2011, p.22-23). 
A reação fisiológica de Ma-Hôre ao respirar o ar próprio dos visitantes pode ser relacionada ao fascínio exercido pelos avanços técnicos sobre culturas situadas à margem do desenvolvimento tecnológico hegemônico - e marginal, nesse sentido, é o planeta Talôi e a civilização que ele abriga. Assim, o medo e a cautela, diante do que se coloca como superior, são substituídos por um inebriar que varre para longe o senso crítico.

Cabe ensaiar uma relação entre a acrítica euforia que domina MaHôre e o efeito provocado nos consumidores da indústria cultural. Nas palavras de Adorno e Horkheimer, em Dialética do esclarecimento,

Atualmente, a atrofia da imaginação e da espontaneidade do consumidor cultural não precisa ser reduzida a mecanismos psicológicos. Os próprios produtos - e entre eles em primeiro lugar o mais característico, o filme sonoro - paralisam essas capacidades em virtude de sua própria constituição objetiva. São feitos de tal forma que sua apreensão adequada exige, é verdade, presteza, dom de observação, conhecimentos específicos, mas também de tal sorte que proíbem a atividade intelectual do espectador, se ele não quiser perder os fatos que desfilam velozmente diante de seus olhos (2006, p.104-105).

Como o ar que os alienígenas tecnologicamente desenvolvidos respiram, a indústria cultural nubla por meio de artifícios técnicos a percepção das coisas. Se o filme (o exemplo adotado por Adorno e Horkheimer, ao qual hoje se poderiam adicionar outros) pode apresentar uma conformação que não é real, também o ar colore de maneira ilusória a realidade diante do homúnculo, impedindo que ele reaja adequadamente a uma situação nociva. Seguindo tal 
linha interpretativa, há no conto um registro ficcional da técnica como uma apaziguadora maneira de dominar, sem para tanto fazer uso explícito da violência e da coação. É a indústria cultural, como o ar da euforia, uma forma de dominar culturalmente o outro.

A reação dos visitantes para com o homúnculo é marcada, também, por uma pretensa superioridade cultural e física. Tratamno como a um animal de estimação: observam com prazer seus gestos e até parecem nutrir por ele um relativo carinho, mas não lhe concedem o direito à autonomia, à escolha. Depois de aparelhá-lo com um escafandro (aqua-lung, conforme o narrador) que o deixa livre do efeito intoxicante da atmosfera da espaçonave, permitem que ele desenhe em uma tentativa de comunicação:

(...) com traços rápidos, desenhou a nave, a escotilha aberta; sobre essa escotilha desenhou-se a si mesmo, na atitude clássica do mergulhador, a pular para a água lá embaixo. Pedia para ir embora, é claro.

Mas o comandante, fazendo que não entendia a súplica desenhada de Ma-Hôre, deu algumas ordens rápidas aos tripulantes. Cada um ocupou seu posto; antes porém instalaram o pequeno hóspede que esperneava, recalcitrante, num assento improvisado com algumas almofadas (QUEIROZ, 2011, p.24).

O olhar que tripulantes da espaçonave voltam para o pequeno Ma-Hôre também encontra paralelos com especificidades históricosociais brasileiras, ainda segundo Ginway. Nas palavras da autora,

o tratamento do pequeno alienígena, que é tão indiferente e todavia amigável aos humanos cientificamente avançados e fisicamente maiores, é reminiscente das atitudes estereotipadas $\mathrm{e}$ 
paternalistas das sociedades tecnológicas diante de outras culturas mais exóticas (2005, p.55).

Logo a nave abandona o planeta e ganha o espaço sideral, afastando-se da galáxia de Ma-Hôre, nomeada W-65. Confrontado com seu planeta reduzido a uma pequena esfera dourada mergulhada na escuridão espacial, Ma-Hôre chora. Nem assim os tripulantes se compadecem, e o homuncúlo se vê reduzido a mascote da espaçonave em uma longa viagem pelo espaço. Resolvem mantê-lo cativo, pouco importando seus desejos.

Seu temperamento se mostra, para os tripulantes, dócil e solícito, e sua inteligência, bastante privilegiada: em pouco tempo aprende a linguagem deles e consegue se comunicar, narrando histórias de seu povo e descrevendo particularidades da vida em Talôi. Não há apreensão de sua alteridade por parte dos "gigantes", contudo: o homúnculo continua a ser tratado como um animal de estimação ou, quando passa a ajudar na manutenção do "cérebro eletrônico" a comandar o funcionamento da espaçonave, um servo.

A docilidade, porém, é apenas aparente. Na conclusão do conto, a docilidade do alienígena se mostra enganosa:

Visitou os tripulantes nos seus beliches: dormiam, sim. Dirigiu-se em seguida ao aparelho condicionador do ar e mudou a posição dos botões de dosagem. Em breve um cheiro forte encheu a nave e Ma-Hôre voltou a sua cabina, onde esperou uma hora. Pôs de novo o aqua-lung e saiu. De um em um tateou o pulso dos astronautas: não batiam mais. Por segurança, Ma-Hôre esperou mais uma meia hora e fez segundo exame: os homens estavam mortos, bem mortos. 
Com gestos seguros, ele abriu uma válvula e deixou que se escapasse para fora o ar envenenado; findo o quê, regulou o preparo de um ar novo - o bom, o doce ar de Talôi. Liberto do aqua-lung, respirou forte e fundo, com um sorriso feliz.

Cantarolando, dirigiu-se ao cérebro eletrônico: e repetiu, como num rito, as complicadas manobras que o comandante lhe ensinara para o deter. Copiou numa fita nova, cuidadosamente invertidos, os dados com que o cérebro fora alimentado de W-65 até aquele ponto. Pôs a fita na fenda, apertou os botões - fiel ao que aprendera do pobre comandante, agora ali tão morto, com o rosto esfogueado pela barba ruiva.

E afinal foi espiar pela vigia, para ver se o céu mudara na marcha de regresso para a terra dos Zira-Nura (QUEIROZ, 2011, p.27-28).

Ma-Hôre, assim, apropria-se da tecnologia dos tripulantes para retornar ao seu mundo. A conclusão do conto dá a entender que toda a docilidade antes demonstrada servia ao propósito de fingir uma domesticação - estratégia à disposição para o homúnculo prevalecer em seus próprios termos. Apenas superficialmente ele se curvou às imposições dos dominadores. A apropriação é a solução forçada ao homúnculo, sem a qual ele se veria privado das próprias especificidades, reduzido às funções arbitrariamente impostas pelos tripulantes da espaçonave. Trata-se de um elemento crucial do enredo para a compreensão da apropriação da ficção científica promovida por Queiroz em "Ma-Hôre”.

Conforme Ginway, o conto

é no fim uma fantasia sobre ser capaz de usar as ferramentas da tecnologia contra os pretensos 
colonizadores, para afirmar o poder da periferia. Ma-Hôre é um trickster, capaz de se apropriar das ferramentas da tecnologia para os seus próprios objetivos, voltando-as contra os usurpadores que subestimaram e subvalorizaram sua cultura. Nesse sentido, Ma-Hôre pode ser comparado a Prometeus, que ousou roubar o fogo dos poderosos deuses. Embora a própria cultura de Ma-Hôre considere o fogo como o seu inimigo, ele consegue comandar a espaçonave, o equivalente moderno do fogo, isto é, a tecnologia. Como em Frankenstein, de Mary Shelley, a história parece avisar que o Brasil, como Ma-Hôre, não deveria ser tentado pelo poder da ciência e da tecnologia, e se satisfazer com sua própria cultura não-tecnológica (2005, p.56).

A ação de Prometeus, bem como a de Frankenstein, pretende subverter a ordem em curso, e subversiva é também a ação do homúnculo. Inverte a condição vigente, toma o poder das mãos dos mantenedores do status quo. Ao contrário dos personagens mencionados, já fixados na tradição, Ma-Hôre não é punido por sua ousadia: seus intentos ocultos se vêem realizados no desfecho do conto.

Como se pode notar, a análise aqui empreendida é majoritariamente calcada na leitura de Ginway, mas na citação anterior há um ponto de divergência: para a crítica, o conto possui um caráter cautelar, segundo o qual o Brasil não deve se apropriar de avanços oriundos de outras culturas. O caso parece ser o contrário: embora a derradeira frieza do homúnculo cause sobressalto no leitor, é por meio da apropriação da tecnologia alheia que ele consegue se libertar do cativeiro. A apropriação é, portanto, investida de um valor positivo. 
Tomando a própria ficção científica como gênero oriundo do centro (em oposição à margem onde se situaria o Brasil), Queiroz adota um procedimento de certa forma análogo ao de Ma-Hôre. Para Ginway, "ela se apropria do gênero ficção científica e o volta contra os paradigmas americanos para servir ao propósito de afirmar a sua própria visão de mundo humanista e antitecnológica" (2005, p.56).

São duas instâncias complementares, portanto, que garantem uma espécie de unidade ao conto e aos seus propósitos: os procedimentos adotados pelo protagonista se equiparam aos de que se valem a ficcionista. A ficção científica equivale à própria espaçonave que Ma-Hôre precisa aprender a manusear para fazer valer sua vontade, para realizar propósitos que dizem respeito às especificidades de seu povo. O inebriar que os avanços técnicos podem provocar precisa ser superado para que tal aconteça: não a replicação acrítica dos paradigmas estrangeiros, mas o manejo crítico deles. Em outras palavras, a fascinação frente aos produtos da cultura de massa importada precisa ser superada, sendo necessária uma apreensão que sirva aos propósitos e aos interesses locais, numa postura autoafirmativa.

Cabe repensar as dinâmicas tradicionalmente postas em cena na abordagem das relações entre nossa literatura e a "metropolitana", à luz das estratégias manipuladas por Queiroz e por Ma-Hôre. Acerca de como nossa crítica canônica abordou tais relações, Candido, por exemplo, apresenta um esquema arbóreo em Formação da literatura brasileira: momentos decisivos: nossa literatura seria um "galho" da portuguesa. Em suas palavras: 
A nossa literatura é galho secundário da portuguesa, por sua vez arbusto de segunda ordem no jardim da Musas... (...)

Comparada às grandes, a nossa literatura é pobre $e$ fraca. Mas é ela, não outra, que nos exprime. Se não for amada, não revelará sua mensagem; e se não a amarmos, ninguém o fará por nós (2007, p.11-12).

De acordo com tal visada, a literatura brasileira é necessariamente derivada e, nesse sentido, "menor". Traçando um paralelo com o homúnculo do conto de Queiroz, tal perspectiva se conforma ao papel imposto pelos tripulantes da espaçonave, incapaz de levar à reviravolta e ao controle do cérebro eletrônico. Aceita a inferioridade de estatura de bom grado, como que grato pela benevolência dos gigantes; aprende como funciona o cérebro eletrônico e trabalha em sua manutenção, mas não consegue alterar-lhe as diretrizes.

O conto põe em cena tais questões por meio de procedimentos próprios da ficção científica, responsáveis por promover uma visada distinta sobre o real a partir de uma apresentação ficcional cognitivamente distanciada. O fomento de um olhar sobre o real que escape às limitações das aparências é, para o teórico Darko Suvin, próprio da ficção científica. Para o autor, conforme exposto em seu estudo Pour une poétique de la science-fiction, a ficção científica é

(...) um gênero no qual as condições necessárias e suficientes são a presença e a interação de distanciamento e conhecimento, e no qual a principal convenção formal é um quadro imaginário, diferente do mundo empírico do autor ${ }^{2}$. (1977)

2 Tradução de "un genre littéraire dont les conditions nécessaires et suffisantes sont la présence et la interaction de la distanciation et de la connaissance, et dont le principal procédé formel est un cadre imaginaire, different du monde empirique de l'auteur" (SUVIN, 1977, p.15). 
Dessa forma, o quadro imaginário "distanciado" que "Ma-Hôre" configura é capaz de promover um olhar cognitivamente diverso do senso comum, um olhar desconfiado das enganosas superfícies. Extrapolando o que é observável no mundo palpável, o conto traça paralelos potencialmente capazes de colocar segundo um novo ângulo as dinâmicas empiricamente verificáveis entre a margem e o centro, além de estabelecer o fascínio pela técnica como possível instrumento de dominação.

No retorno ao real, o conto denuncia uma espécie de domesticação cultural sofrida por países à margem do desenvolvimento, como o Brasil. Na conclusão do conto, há uma utópica abertura para o futuro, quando Ma-Hôre faz uso de um conhecimento que não é mais alheio à sua cultura, um conhecimento já incorporado à sua experiência e, portanto, já constitutivo de sua feição cultural. É possível, assim, alterar as tendências em curso.

"Ma-Hôre" fornece um exemplo que força a reavaliação da dinâmica entre o centro hegemônico e as culturas periféricas, capaz de abordar a apropriação com fins de autoafirmação e não de submissão e replicação de paradigmas alienígenas. Trata-se de uma apropriação que tem o propósito de subverter o que é oriundo dos pretensos "gigantes": apropriar para dominar o dominador e fazer valer as próprias especificidades. 


\section{REFERÊNCIAS}

ADORNO, Theodor Wiesengrund; HORKHEIMER, Max (1985). Dialética do esclarecimento. Fragmentos filosóficos. Tradução de Guido Antonio de Almeida. Rio de Janeiro: Jorge Zahar.

CANDIDO, Antonio (2007). Formação da literatura brasileira: momentos decisivos. 11. ed. Rio de Janeiro: Ouro sobre Azul. . (1999). Iniciação à literatura brasileira. São Paulo: Humanitas.

COUTINHO, Afrânio (s.d.). Conceito de literatura brasileira. Rio de Janeiro: Ediouro.

GINWAY, Mary Elizabeth (2005). Fiç̧ão cientifica brasileira: mitos culturais e nacionalidade no país do futuro. Tradução de Roberto de Sousa Causo. São Paulo: Devir.

QUEIROZ, Rachel de (1961). "Ma-Hôre". In: DÓREA, Gumercindo Rocha (Org.). Histórias do acontecerá. Rio de Janeiro: Edições GRD.

SODRÉ, Muniz (1973). Ficção do tempo: análise da narrativa de science fiction. Petrópolis: Vozes.

SUVIN, Darko (1977). Pour une poétique de la science-fiction. Québec: Les Presses de L'Université du Québec.

TAVARES, Braulio (2011). "Rachel de Queiroz". In: TAVARES, Braulio (Org.). Páginas do futuro: contos brasileiros de ficção científica. Rio de Janeiro: Casa da Palavra. 